\title{
Nacimiento, evolución y crisis de la prensa femenina contemporánea en España
}

\author{
María Ganzabal Learreta \\ Dra. en Ciencias Sociales y de la Comunicación por la Universidad del País Vasco. \\ Actualmente es Profesora del Departamento de Comunicación Audiovisual y Publicidad de la \\ Universidad del País Vasco.
}

\section{Resumen}

Este artículo pretende analizar la historia de la prensa femenina actual en España. Una historia determinada por el desembarco a mediados de los 80 de los grandes grupos editoriales internacionales.

Un fenómeno que determinó la existencia de muchas publicaciones españolas que ya existían y que tuvieron que remodelarse como Telva o que desaparecieron, como Ama y Dunia.

Un mercado de la prensa femenina que se ve convulsionado otra vez por la aparición estos días de nuevas cabeceras: Nova, In Style, Chic, Psychologies, Citizen K...dirigidas a los más de 4 millones de españolas que leen este tipo de prensa.

\section{Abstract}

This article is an attempt to analyse the history of the modern women's press in Spain. It is a history determined by the arrival in the mid'80s of the large international publishing groups.

This phenomenon determined the fate of many publications which already existed and had to be redesigned as is the case of Telva or which simply disappeared, as Ama and Dunia.

A women's press market which is now again convulsed by the appearance of new tittles: Nova, In Style, Chic, Psychologies, Citizen K... aimed at the more than 4 million Spanish women who read this type of publication.

Palabras clave: revista, femenina, mujer, editorial, remodelación

Key words: magazine, women's press, woman, publishing group, redesign

\section{NACIMIENTO, EVOLUCIÓN Y CRISIS DE LA PRENSA FEMENINA CONTEMPORÁNEA EN ESPAÑA}

erá en los años sesenta cuando comience la prensa femenina en España tal y como la conocemos hoy en día. En esta época, algunos grupos empresariales se interesan por las publicaciones dirigidas a las mujeres siguiendo los patrones de las revistas femeninas que ya existían en países como Francia, Inglaterra...

Una revista creada precisamente en 1960 y patrocinada por el CGA (Comisaría General de Abastecimientos) es Ama del grupo Montiel. Ama sobrevivirá junto a Telva, convirtiéndose en las dos revistas más importantes de la década de los sesenta, hasta la aparición de Dunia en los años setenta. 
En esta misma época, Sarpe, una editorial cercana al Opus Dei decide lanzar una revista quincenal (desde 1989 y hasta la actualidad será mensual) dirigida especialmente a la mujer. Así en Octubre de 1963 nace Telva. Esta revista que tomaba para su título un nombre de mujer proveniente de la literatura asturiana, popularizado también por el inolvidable Alfonso con sus tiras cómicas de Telva y Pinón, llegó al mercado emulando a los grandes títulos dirigidos a la mujer.

En 1982 un grupo de profesionales provenientes de la propia editora, compran la cabecera de Sarpe y se convierte en Ediciones Cónica, con lo que consigue aumentar su tirada en 30.000 ejemplares. Aunque en 1994 hay un intento de internacionalizar la revista editándola en Argentina, fracasará en el 95. Actualmente y tras 40 años en el mercado, es Recoletos Grupo de Comunicación quien posee el 99,06\% del capital de Ediciones Cónica.

La aparición de Telva supuso una ruptura en el modelo de la prensa femenina. Fue la primera revista femenina en sentido moderno (aunque representaba los valores más tradicionales de la mujer, esto son: dios, matrimonio e hijos). Telva, con Pilar Salcedo como primera directora, deja clara su línea ideológica desde la página de su primer editorial donde señala lo siguiente: "Soplan por el mundo corrientes de renovación, de desarrollo económico; se abren a la mujer nuevos horizontes y es preciso vivir a la altura de las circunstancias. Eso de "los derechos de la mujer" suena bien pero hay que estar a las duras y a las maduras. Le es preciso estar bien informada para que, al aprender los derechos, entienda en ellos el deber de trabajar -a escala europea- con una mayor seriedad y eficacia

En esta misma época, surgen otras revistas como Belleza y Moda (RBA Revistas, S.A.) que nace en 1969 o Greca del grupo editor Sarpe (que en 1984 lanzará al mercado la revista Cómplice) que surge en 1976.

Sin embargo, la verdadera revolución, tanto por la orientación como por la incursión del primer grupo editorial extranjero, la multinacional alemana Bertelsmann, con su filial editora de revistas, Gruner \& Jahr $(G+J)$ en España, viene de la mano de Dunia, también quincenal hasta que terminará por ser mensual (1993). Dunia, que nace en mayo de 1976 de la mano de Editora Nueva España, es adquirida al año de su aparición por el grupo alemán $\mathrm{G}+J$.

Dunia dio un paso al frente en la evolución de la mujer. España vivía una época de transición tanto política como social y se empezaron a demandar determinados temas hasta entonces poco habituales o ausentes de los medios de comunicación.

Dunia fue una revista novedosa, "para la nueva mujer" decía en su lema. Toda esta ideología queda resumida en el primer editorial de Dunia señalando que:

"En tus manos querida lectora tienes el primer número de Dunia: una revista inteligente para la mujer. Si la curiosidad te ha llevado a ojearla antes de leer esta presentación, no queremos insistir en nuestros propósitos: ti misma, estamos

\footnotetext{
${ }^{1}$ Este editorial corresponde a la página ำ5 del primer número de la revista Telva, que salió en octubre de 1963. La revista tenía 56 páginas y se vendía a 6 pesetas.
} 
seguros, lo has descubierto. Si por el contrario esto es lo primero que lees, confiamos en que sigas con ella en tus manos. Todos sabemos que el campo de interés femenino ha ampliado sus fronteras y ha sufrido una lógica e importante transformación. La inteligencia de la mujer se mide hoy, tanto por su capacidad para abordar temas típicamente femeninos: modas, labores, cocina, como por su interés por todo aquello que ha entrado en su órbita y cuyos conocimientos la estimulan y ayudan en su lucha hacia nuevas metas.

Inteligencia y feminidad son dos conceptos que nunca deben separarse. Por eso Dunia quiere ofrecértelos unidos. Nuestras páginas te hablarán de muchas cosas que ya conoces, y de otras facetas de la vida actual que te gustaría dominar: psicología, arte, medicina, leyes, teatro... campos que por su continua evolución nuestra revista te los brinda actualizados para mantenerte siempre al día. Queremos, para terminar, pedirte un favor: tu colaboración. Tus sugerencias y opiniones. De esta forma, Dunia será no solamente lo que nosotras queramos, sino el resultado de una labor conjunta, y, por ello, infinitamente más interesante. Nos despedimos de ti, querida amiga, con la ilusión de que volveremos a encontrarnos"

Las mujeres se sintieron identificadas con ese modelo de mujer que proponía esta revista y tuvo un enorme éxito. Para la profesora Juana Gallego este éxito se debió principalmente a que la revista supo conectar con un importante número de mujeres que se identificaba con:

- Una mujer inteligente, como manifestaba la revista.

- Cuyo campo de actuación se había ampliado (trabajo, interés cultural, políti$\mathrm{co} . .$.

- Pero que, sin embargo no abandonara drásticamente el rol femenino, que no vulnerase la feminidad.

Aunque ya hemos hablado de revolución al referirnos a Dunia, hay que decir sin embargo que la verdadera revolución "a nivel internacional" no empieza en España hasta el otoño de 1986 cuando se produce la entrada de los grandes grupos de prensa internacionales.

La promulgación de la Ley sobre inversiones extranjeras en empresas editoriales (1982), la entrada de España en la CEE, la aparición del Reglamento que regula las inversiones extranjeras en editoriales (1986) y la creación del mercado único europeo en 1992 hicieron que los grupos de prensa que editaban revistas dirigidas a la mujer centraran su atención en España. Así pues, los grupos extranjeros pudieron invertir sin trabas en cualquier empresa periodística española ${ }^{4}$.

\footnotetext{
${ }^{2}$ El primer número de la revista Dunia apareció en mayo de 1978. La revista cerraría en 1998

${ }^{3}$ GALLEGO, J (1990): Mujeres de papel. De Hola a Vogue: La prensa femenina en la actualidad, Icaria: Barcelona .p.70

En esta misma época se lanzó la versión norteamericana de Cosmopolitan, una versión mucho más agresiva que esta mujer de Dunia, donde la feminidad de ésta quedaba totalmente transgredida por el descaro de la americana, con su consabido fracaso.
} 
La competencia se hizo cada vez más fuerte sobre todo para las editoras españolas que sentían la presión de las grandes inversiones realizadas por las editoriales extranjeras.

Así en el 25 aniversario de Telva, Juan Kindelán, Consejero Delegado de Ediciones Cónica resume los años de existencia de la revista:

"Celebra Telva sus primeros veinticinco años cuando se produce una auténtica revolución en el mercado de la llamada prensa femenina en España. Telva, que convivió parte de este largo periodo con Ama y luego con Dunia, da la bienvenida alborozada a los muchos títulos extranjeros que de pronto han caído en la cuenta de la importancia cuantitativa y cualitativa de la mujer española, irrumpiendo en los quioscos al peso, como nuevos ricos. El saludo es sincero y alegre, entre otras razones porque ha sido precisamente en esos meses cuando Telva ha conseguido el mayor crecimiento de su historia, seguramente espolvoreada de sana competencia”,

No sólo Telva, sino que todas las revistas eran optimistas y veían esta incursión de nuevos títulos con buenos ojos. Así, por ejemplo, Sara Glattstein, antigua Directora de Dunia reconocía el peligro de invasión de las nuevas editoriales enfatizando en la dureza de la competencia y en el peligro del descenso de ventas. Para Ana Rosa Semprum (en esa época Directora de Marie Claire 16), la competencia se veía asociada con el aumento de calidad del producto. Por su parte, José Luis Casado, Director Comercial de Elle creía que esta competencia supondría un crecimiento para el mercado aunque algunas publicaciones que ya estaban habían perdido ventas y lectoras ${ }^{6}$.

Todas las revistas se dan cuenta del inevitable desembarco extranjero y hacen hincapié en el desfase que lleva España respecto de los demás países señalando lo reducido de las tiradas españolas y del número de títulos si lo comparamos con las revistas europeas. Como justificación de esto se destaca los 50 años de tradición lectora que existen en otros países y que en España no existían.

Como ya hemos señalado antes, Gruner \& Jahr que fue la primera multinacional que entra en el mercado español comprando Dunia, lanzará en 1986 Mía (una revista semanal y con fuerte contenido práctico que ha llegado hasta nuestros días) ${ }^{7}$.

\footnotetext{
${ }^{4}$ GALLEGO, J (1990): Mujeres de papel. De Hola a Vogue: La prensa femenina en la actualidad, Icaria: Barcelona .p.71

${ }^{5}$ Este es el editorial del no 583 de la revista Telva correspondiente a octubre de 1988 cuando acababan de aparecer en el mercado español revistas como Elle, Vogue o Marie Claire

${ }^{6}$ Son las impresiones de los principales directores de revistas femeninas ante el inevitable cambio de supone la incursión de capital extranjero en el mercado. FERNANDEZ DEL VADO, S (1988): "Revistas femeninas. Un pastel de rica miel", Ipmark, nำ17, 16-31 octubre, p.58

${ }^{7} \mathrm{G}+\mathrm{J}$ lanzará a finales de 1996 la revista Vera como estrategia de defensa de su semanario práctico Mía ante el nacimiento de Gracia (Aaron Press; André Neves) que se produciría en febrero de 1997, aunque ambos cerrarán meses después.
} 
El segundo grupo editorial internacional en orden de aparición en España fue el francés Hachette Filipacchi con el lanzamiento en octubre de 1986 de la versión española de Elle, dirigida por Mª Luisa Malibrán. En 1989 surgirá Elle Decoración que al principio se venderá independientemente, pero que luego se convertirá en suplemento de Elle ante la recesión publicitaria de este segmento de revistas.

Otra revista que hace su incursión en España a finales de 1987 es Marie Claire 16 (en Francia desde 1937) que es editada por el grupo francés Álbum y por la editora germana $\mathrm{G}+\mathrm{J}$. El Grupo 16 adquirió los derechos de la revista francesa en nuestro país e invirtió 300 millones en su lanzamiento. Con el éxito de Marie Claire, surge La Casa de Marie Claire 16.

Respecto a Vogue, se intentó introducir en el mercado español en el año 8081 editándose desde Francia, pero por problemas legales, el proyecto fracasó. Solventados estos problemas en marzo de 1988, se introduce definitivamente en el mercado español en abril del mismo año de la mano del editor brasileño Luis Carta y con Ana Puértolas como directora de la misma. Un estudio de Sofemasa para Condé Nast, previo al lanzamiento, subrayaba que Vogue contaba con una excelente imagen en nuestro país, donde era conocida principalmente por sus ediciones anglosajonas ${ }^{8}$.

Vogue, editada por Conde Nast, S.A. tiene unas cuarenta publicaciones en casi todo el mundo, siendo pionera la edición del Vogue americano con más de un siglo de trayectoria. Como la definió Luis Carta "Somos elitistas y no nos dirigimos a cualquier mujer. La mujer Marie Claire o Elle son de clase media, trabaja pero no es directiva y en cierta forma aprende a vivir. La de Vogue tiene 30 años, si trabaja es directiva, sino tiene dinero por familia o por matrimonio, pero es una mujer abierta mentalmente, que si bien gusta de pequeños consejos no necesita que le expliquen como tener un orgasmo... La diferenciación vendrá dada por el precio y por el contenido. Vogue sale a la calle al precio de 350 Pts., y un vestido de Vogue deberá costar por lo menos 10 veces más que uno de Marie Claire","

Junto a Joyce que se puso a la venta en abril de 1990 surge Cosmopolitan en octubre de 1990 de la mano de $G+J$ y Hearst Corporation y bajo la dirección de Sarah Glattsein Franco. Tras un leve intento de introducir esta revista en 1976 y su correspondiente fracaso, será ahora cuando triunfe y se consolide en el mercado.

La verdadera novedad de esta revista fue la nueva forma de tratar el tema sexual y esto ha hecho que muchas otras se decidan a incluirlo entre sus páginas, pero insisten en señalar la primicia de la revista en este tema. Tanto es así, que editores de revistas de la competencia la calificaron en su día de "psicosexy". También destaca otra de las principales características de esta revista como es su gran

\footnotetext{
${ }^{8}$ Luis Carta poseía licencia para editar Vogue en Latinoamérica pero no en España. Para ello, constituyó en Madrid la sociedad Ediciones Condé Nast, participada casi en su totalidad por el grupo multinacional (98\%) el 28 de septiembre de 1987
}

${ }^{9}$ FERNANDEZ DEL VADO, S (1988): "Revistas femeninas. Un pastel de rica miel", Ipmark, №317, 16-31 octubre, p.60 
contenido editorial para "ser leída". Por último señalar también el carácter optimista y el tratamiento de los temas con un carácter alegre y jovial.

Woman nace en Septiembre de 1992 como una revista tan española como lo es Telva. De la mano del Grupo Zeta, llega al mercado destacando con un tamaño superior al normal, 235x 333mm (diversas modificaciones formales le llevarán a homogeneizar su tamaño al de las demás revistas actuales). Su carácter español, que viene dado por su grupo editor, por su directora Joana Bonet (actual directora de Marie Claire) no ha sido un handicap en las ventas. La revista nace con una mentalidad semejante al de las grandes revistas internacionales: modelos de sobra conocidas a nivel internacional, importancia del diseño gráfico, director de arte, reportajes, entrevistas de temas internacionales y hasta el nombre de "mujer" en inglés, es decir, todos los requisitos para competir con las grandes revistas.

A modo de resumen se puede decir que si Telva pertenecía a la primera generación de revistas femeninas (elevar el rol de ama de casa a status), Dunia pertenece a la segunda generación (hacer del status de la mujer un rol activo: su slogan fue "para la mujer inteligente", como si las lectoras de Telva no lo fueran). Elle, Marie Claire, Vogue y Cosmopolitan pertenecen a la tercera generación. Son títulos míticos a nivel internacional. Woman pertenece a la cuarta generación de revistas: española pero con aire de gran revista internacional.

\section{REMODELACIÓN DEL SECTOR}

Esta entrada masiva de prensa internacional en España perjudicó notablemente a las dos que ya existían entonces que eran Telva y Dunia. Esto explica que los índices de audiencia y facturación publicitaria cayeran en picado, y que se iniciara un proceso de reestructuración.

En un principio se pensó que la adaptación de la revista al nuevo mercado iba a ser sencilla. En el 77 había un enorme hueco en el mercado y había unas lectoras hambrientas de información que no se identificaban con ninguna revista existente. En el 78 Dunia pasa a la periodicidad quincenal, tirando de las lectoras del sector hacia el europeísmo. Dunia tuvo que cuidar más el producto, investigar mejor el mercado y ver a qué clientes había que dirigir la atención. En los 80 se consolida su liderazgo y la competencia empieza a reaccionar, a remodelarse siguiendo en muchos casos los pasos de la propia revista.

Así en noviembre de 1993, tras muchos otros intentos de lavado de imagen (1988: "Ya hicimos escuela, ahora queremos hacer época") y ante la imposibilidad de cerrarla ó de cambiarla de nombre debido a los 70.000 fieles compradores, $G+J$ lanza una "nueva Dunia". En realidad más que un relanzamiento o un cambio de imagen se trata más bien de una nueva publicación, de una fórmula editorial distinta a la anterior aunque se ha mantenido la misma cabecera.

Desde Julio de 1993 la revista vuelve a ser mensual como ya lo fue en sus dos primeros años de existencia, periodicidad que fue cambiada por $\mathrm{G}+\mathrm{J}$ cuando 
adquirió la cabecera en 1977 a Editora Nueva Europa dirigida por Vicente Boadilla y la convirtió en quincenal.

En este lanzamiento de Dunia colaboró el grupo Hearst. Así la nueva Dunia era la aplicación en nuestro país de una fórmula editorial implantada por Hearst en Estados Unidos desde 1903 con la revista Reebook cuya difusión ronda los 3,4 millones de ejemplares.

La nueva Dunia apareció con un formato mayor y con una cabecera renovada. Se aumentó su tirada hasta los 225.000 ejemplares y su precio se redujo a 300 pesetas. Su tarjet de mujer era el siguiente: "Se trata de una mujer entre los 25 y los 35 años, "activa, moderna, abierta, con clase y estilo". Esta nueva mujer se caracteriza por un problema de falta de tiempo y de distribución de éste entre las tres facetas que conforman su vida: la pareja, los hijos y el trabajo. Este último determina claramente el contenido editorial de la revista, de modo que sin abandonar los temas de moda y belleza (40\% aprox.) la nueva Dunia concede una especial importancia a todos los temas relacionados con estas tres facetas y, en definitiva "con el entorno emocional de la mujer"

Una de las características diferenciadoras de Dunia respecto de las demás revistas es la creación de una sección especial para el tema de los hijos. Será esta sección junto con la relacionada con el tema de la pareja, el trabajo y las relaciones, el verdadero plato fuerte de la revista.

El optimismo del grupo editorial $G+J$ era claro ante esta última remodelación. Era indispensable que esta revista, tan antigua ya en el mercado, sufriese una importante renovación tanto estética como de contenido si quería competir con las revistas que existían en ese momento.

Estos cambios estéticos y de contenido fueron principalmente acompañados de cambios en la dirección de la revista. Un sinfín de directoras como María Eugenia Alberti, Sarah Glattsein, Karmele Setién, Ketty Rico, Milagros Valdés, Teodoro Izquierdo, Elena Martínez y la última, Mara Malibrán en 1997.

Fue precisamente esta última y su equipo los que decidieron en plena crisis de la revista, dar un nuevo enfoque a ésta para diferenciarla del resto de las mensuales, pero la introducción de más reportajes y temas prácticos, no logró contactar con un público femenino, quizás demasiado acostumbrado a ver Dunia como una revista de moda y belleza. Estos cambios no ayudaron a la crisis de ventas que la revista llevaba arrastrando desde 1990 y en 1998 se decide cerrar la revista.

La decisión de $\mathrm{G}+\mathrm{J}$ de no entrar en la estrategia de promociones y los regalos, motores que actualmente impulsan las ventas de la mayoría de las revistas mensuales femeninas influyó notablemente en su cierre además de un descenso en las ventas en 1997 (26\% menos que en 1996). 


\section{GRÁFICO 1}

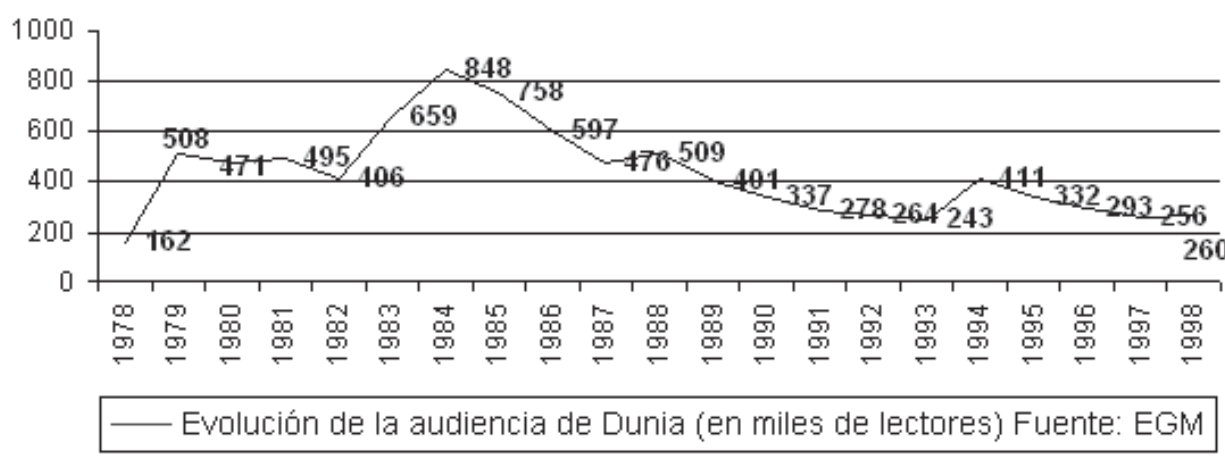

GRÁFICO 2

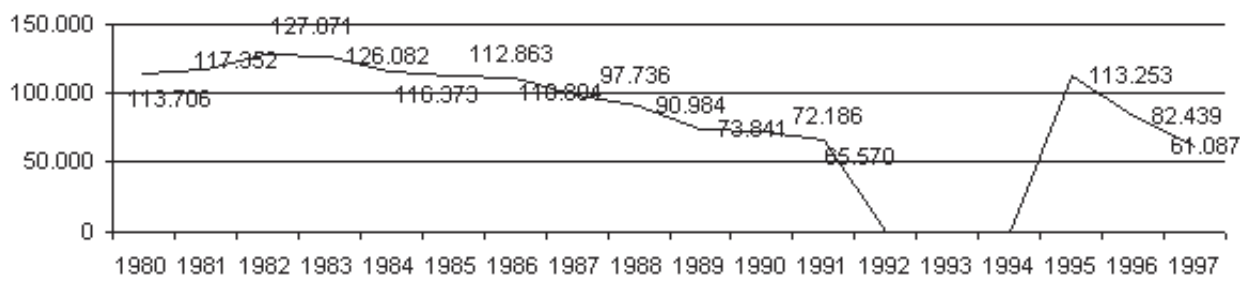

Difusión de Dunia que a partir de 1993 se transforma en mensual

Telva ha sido la "otra gran revista nacional" que ha estado obligada a hacer nuevos replanteamientos ante la entrada de capital extranjero. Con un nuevo slogan "El gusto es nuestro" se presentaron los nuevos cambios. La principal novedad como ya he señalado antes es la adquisición por Ediciones Cónica filial de Punto Editorial, grupo en expansión que había sido iniciado por Juan Pablo de Villaneuva y Juan Kinderlán al consumarse la ruptura de ambos con Sarpe y adquirir esta última la revista La Actualidad Económica. En 1982 "Punto Editorial" compra Telva a Sarpe por 100 millones de pesetas.

Entre las transformaciones que ha sufrido la revista, está la de convertirse en mensual a finales de 1989. Es en este año cuando adquiere las características propias del segmento: encuadernado al lomo, más páginas, mejor papel... El resultado fue espectacular y la tirada aumentó en más de 30.000 ejemplares. 
La estrategia de la revista para soportar la fuerte competencia ha sido la de aumentar páginas, nuevas secciones, más color, nuevo formato, nuevo diseño y grandes reportajes exclusivos. Ideológicamente, Telva ha variado muy poco o nada. Fiel a su primera línea editorial muy conservadora, se mantiene un poco al margen de las demás revistas al ignorar por completo temas relacionados con la sexualidad, la pareja si no es dentro del matrimonio...Esta continuidad ideológica se ve reflejada también en el escaso número de veces que la revista ha cambiado su dirección: Pilar Salcedo, Covadonga O'Shea y su actual directora, Nieves Fontana.

Hoy en día, Telva es la única gran revista femenina que continúa en el mercado tras 40 años de vida. Su lucha titánica, sobre todo con cabeceras españolas como Ama, Dunia y su sostenimiento frente a las internacionales le dan la victoria. Desde 1997 la revista sigue con un lento crecimiento pero sobre todo con una gran fidelidad por parte de la audiencia cuya media está en los 163.000 ejemplares vendidos y los 212.667 lectores. (OJD y EGM 2003)

\section{GRÁFICO 3}

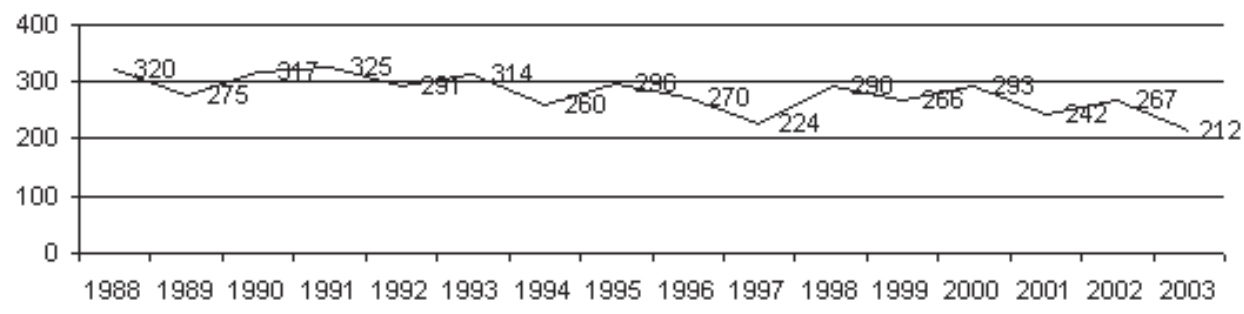

— Evolución de la audiencia de Telva (en miles de lectores) Fuente: EGM

\section{GRÁFICO 4}

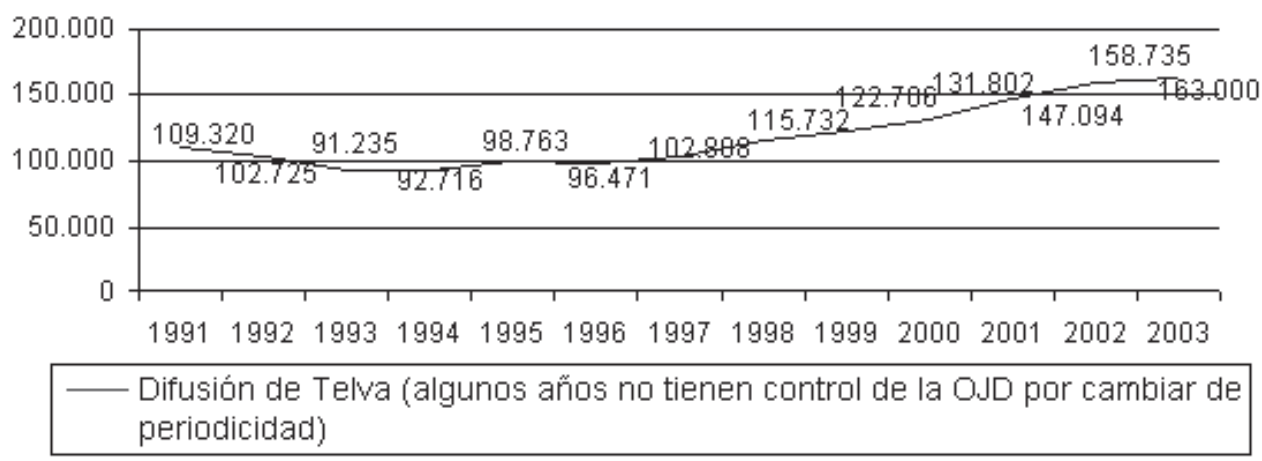


$414 \quad$ Nacimiento, evolución y crisis de la prensa femenina...

Sería interminable la lista de publicaciones femeninas que tras intentos infructuosos de remodelación no consiguen sobrevivir en este mercado. Uno de ellos es el de Belleza y Moda que también sufrirá varias modificaciones. La última en los noventa. Belleza y Moda había sido una revista mensual que había ocupado una posición marginal dedicada a la cosmética y a la belleza. La revista es relanzada por RBA Editores, sucesora de Editorial Origen y Planeta Revistas respectivamente, desplazándola hacia este segmento aunque manteniendo un fuerte énfasis en su temática tradicional aunque acabará por desaparecer.

El final también se veía claro en el caso de Ama que a pesar de evolucionar con los tiempos hacia un periodismo de servicio no consigue encontrar su hueco en el mercado. En los años sesenta y setenta diversificará sus contenidos hacia una línea de "revista de servicios y corazón". En 1984, y debido a el descenso de ventas y a la reducción del índice publicitario al 10\%, empieza su renovación total en busca de la nueva mujer aunque infructuosamente ya que en enero de 1990 y con Paca Castilla Vergara como última directora cierra definitivamente. Ama llegó a alcanzar los 83.761 ejemplares de difusión, aunque cuando cerró estaba en 69.000 ejemplares de tirada.

A pesar de su desaparición y de no pertenecer al grupo de revistas de "alta gama", Ama ha sido una revista de gran influencia en las revistas prácticas ó lo que Juana Gallego denomina como revista de divulgación y orientación. Su influencia se deja notar en las actuales Mía, Prima, Clara... que no son sino réplicas actualizadas de la anterior.

Tampoco logró sobrevivir en el mercado Cómplice, cuyo último intento de renovación hacia un público más joven en 1988 no dio los resultados esperados, cerrando en 1992. En 1991 desaparece Entorno de Mujer, en 1992 Biba (América Ibérica) y Cómplice (Axel) y Greca (Axel) tras varios intentos de remodelación en 1991 y en 1993, con cambios de dirección (Pepa González, Angeles Aledo), de mancheta, de contenido, de tratamiento de la portada e incluso de periodicidad, terminará cerrando en 1993.

Esto no es más que un claro ejemplo de las auténticas penurias que tuvieron que soportar muchas cabeceras por hacerse un hueco en este nuevo mercado de la prensa femenina.

El resguardo internacional que tienen revistas como Vogue, Marie Claire..., tampoco las excluye de remodelaciones. Por ejemplo, y tras la aparición de la revista Glamour, en 2002 por la editora Conde Nast, con un formato reducido y liderando las ventas de las femeninas, la revista Cosmopolitan sufrió varias remodelaciones, fundamentalmente de forma, puesto que el contenido que tienen es homogéneo y muy bien segmentado. La gran apuesta de Cosmopolitan ha sido su nuevo formato "mini". Una revista igual que la de siempre pero en un formato reducido 17x22 con la intención de llegar a un tarjet con menor poder adquisitivo, más joven y con un tamaño adecuado para leerlo en cualquier parte. 
La internacional Vogue también sufrirá diversas transformaciones ante unos resultados no muy boyantes. Prueba de ello es el largo recorrido de directoras como Cristina Alberdi, Raquele Enríquez, Mara Malibrán, Daniela Cattaneo...Será a partir de 1997 cuando se inicie una segunda etapa de esta publicación que incluye también una ligera reducción de su formato y se estabiliza la dirección de la misma hasta hoy en día con Yolanda Sacristán a la cabeza de la publicación.

\section{NUEVAS PUBLICACIONES}

Una característica del mercado de la prensa femenina es precisamente la facilidad con la que aparecen y desaparecen revistas del mercado. Aunque algunas fracasaron y tuvieron que cerrar, otras apoyadas principalmente por los gigantes editoriales internacionales aparecieron y se hicieron con su hueco en el mercado. Tras unos años de asentamiento de las grandes publicaciones y de cierta estabilidad en el mercado, surgen ahora nuevas publicaciones que intentan actualizarse y cubrir las nuevas necesidades que presenta la mujer hoy en día.

Este es el caso de la revista AR, La revista de Ana Rosa que surgirá a finales de 2001 y de la mano de Hachette. Es la gran oportunidad de lanzar un concepto novedoso e incluso rompedor en España: utilizar el poder prescriptor de un personaje popular, en este caso una mujer popular y con una credibilidad reconocida como es Ana Rosa Quintana. Ahora bien, el tarjet de edad es diferente ya que esta publicación va dirigida a mujeres a partir de 35 años. Las cifras de difusión de la revista se sitúan en 135.900 ejemplares (OJD En-Dic 2003) y una audiencia de 271.000 lectoras (EGM acumulado 2003)

Ya hemos señalado el lanzamiento de Glamour en 2002. Glamour es una cabecera internacional que nació en Estados Unidos hace treinta años y que vende allí más de dos millones de ejemplares. Una revista de tamaño "pocket" al igual que Cosmopolitan que se ha situado a la cabeza de las femeninas con una tirada de 271.166 ejemplares (OJD 2003) y unas 431.000 lectoras (EGM 2003). El secreto de su éxito reside en la calidad de su diseño e impresión (para eso se beneficia de pertenecer a la gran editorial francesa editora de otras revistas como Vogue, lo que pone a su disposición a los mejores fotógrafos, diseñadores...) además de sus contenidos eminentemente prácticos y su precio: 1,8 euros.

Sería imposible citar la cantidad de revistas femeninas que se hacen al mercado. El 2004 ha sido además un año propicio para esto. En una simple enumeración citaría la aparición de Nova (Hachette), Única (Recoletos), Más Sexy (Globos Comunicación) o InStyle de Edipresse Hymsa.

La última gran apuesta revolucionaria española en el campo de las revistas de alta gama es Chic* una revista femenina de alta gama que salió al mercado en octubre de 2004 de la mano del grupo editorial Hola S.A., un grupo centrado en prensa del corazón y dirigida por Isabel Ottino. 
En principio está pensada con carácter independiente de la revista del corazón de esta editora pero con un tarjet de población bastante afín al de esta publicación (mujer urbana de entre 25 y 45 años, de clase alta y media-alta, con estilo propio, que cuida su imagen, con inquietudes por el mundo que la rodea y que desea estar bien informada).

De momento, Chic $^{*}$ será distribuida conjuntamente con la revista Hola! lo que garantiza unas ventas entre 600.000 y 700.000 ejemplares y una difusión de EGM superior a los

2 millones de lectores lo que sin duda supondrá un hecho sin precedentes en las revistas femeninas españolas de alto standing.

Ya en 2005, el grupo francés Hachette lanza Psychologies "la revista de la nueva mujer" dice su lema. Se trata de una revista dirigida a mujeres de 25 a 45 años, con un precio de lanzamiento de 1 euro. Es la versión española de la homónima, que en Francia tuvo una difusión media de 2305.000 ejemplares en 2003-2004 y que fue lanzada en 1997 por Jean Louis Servan-Schreiber.

Citizen $K$ de Focus Ediciones (participada mayoritariamente por Edypresse Hymsa) ha lanzado también en marzo de 2005 esta nueva publicación femenina de carácter trimestral con más de 300 páginas de moda, arquitectura, fotografía, cine.... y donde la mayoría de sus reportajes están importados de su originaria francesa.

\section{GRÁFICO 5}

\begin{tabular}{|l|c|c|c|}
\hline & Grupo editor & Difusión & Audiencia \\
\hline Cosmopolitan & G+J & 223.239 & 793.000 \\
\hline Elle & Hachette & 140.429 & 492.000 \\
\hline Marie Claire & G+J & 101.594 & 280.000 \\
\hline Vogue & Condé Nast & 90.934 & 438.000 \\
\hline Telva & Recoletos & 163.220 & 389.000 \\
\hline Woman & Zeta & 81.556 & 309.000 \\
\hline Glamour & Condé Nast & 271.166 & 431.000 \\
\hline AR La Revista de.. & Hachette & 135.900 & 322.000 \\
\hline Chic & Hola, S.A. & - & - \\
\hline
\end{tabular}

Fuente: OJD 2003 y EGM acumulado 2003 


\section{CONCLUSIONES}

Telva se ha convertido en la gran revista femenina española por excelencia. Una revista que tras cuarenta años en el mercado y con potentes recursos económicos y editoriales tras ella, ha sabido adaptarse a los tiempos. Con un contenido muy "tradicional" y una audiencia muy fiel ha encontrado definitivamente su hueco en el mercado. Un mercado totalmente saturado de publicaciones para la mujer que aparecen y desaparecen con relativa facilidad.

Esta fidelidad de la audiencia ha supuesto que Telva pueda mantener su financiación publicitaria de manera magistral. La publicidad es clave para las editoras de este segmento, que ofrece a los anunciantes un público femenino con alto poder adquisitivo y hábitos de consumo muy desarrollados.

Telva ha podido competir con coetáneas como Dunia pero también ha sabido hacer frente a las clásicas revistas femeninas internacionales. Además ha sabido adecuarse a la fragmentación y a la poca fidelidad del mercado entrando de lleno en la guerra de las promociones y regalos. Si comparamos los índices de audiencia y difusión e inversión publicitaria de esta publicación a lo largo de los años vemos que poco o en nada han variado manteniéndose muy estables e incluso aumentando en la actualidad.

Woman es la otra gran revista española que subsiste en el mercado tras diez años de trayectoria. Tras unos comienzos complicados, ya que su lanzamiento se produjo cuando todas las grandes internacionales acababan de aparecer en 1992, logra mantenerse en el mercado. Con unos índices de difusión y audiencia bastante estables (81.556 OJD 2003 y 298.000 lectoras EGM 2003) ha logrado su consolidación en este segmento.

El desembarco extranjero de grandes publicaciones en España aumentó el índice de lectoras pero también fragmentó considerablemente el mercado y llevo inexorablemente a la desaparición a unas cuantas (el caso de Dunia es el más elocuente) que no supieron enfocar ni encontrar un sitio en el mercado.

El crecimiento de lectoras está íntimamente relacionado con el desarrollo de una pluralidad mucho mayor en el mercado de audiencias femenino, un fenómeno que se corresponde con la mayor oferta de títulos. Esta gran oferta de publicaciones se corresponde con una gran concentración editorial. Son cinco los grupos editoriales: Hachette (AR, Elle, Psychologies), Edipresse/Hymsa (Clara, Mujer21), G+J (Cosmopolitan, Mía, Marie Claire), Condé Nast (Vogue, Glamour) y el Grupo Zeta con Woman los que controlan el $90 \%$ de la difusión de la prensa femenina de alta gama.

Tras los años de asentamiento de las grandes publicaciones internacionales en nuestro país, surgen con los cambios nuevas revistas orientadas a satisfacer los deseos de una nueva mujer que también ha evolucionado en su vida y en sus intereses. Pese a la demostración de que el mercado femenino de alta gama está plenamente saturado, los más de cuatro millones de españolas que se calcula leen 
$418 \quad$ Nacimiento, evolución y crisis de la prensa femenina...

este tipo de prensa se pueden beneficiar de las nuevas incursiones que están acaeciendo estos días. Una nueva época gloriosa para la mujer, para este segmento de publicaciones y para la prensa en general (El Mundo con su suplemento semanal dirigido a la mujer lo Donna) que no renuncia a entrar de lleno en el tema femenino y en sus intereses.

\section{REFERENCIAS BIBLIOGRÁFICAS:}

\section{Libros}

ALTES, E (2000): Imágenes de las mujeres en los medios de comunicación. Líneas actuales de investigación, Instituto de la Mujer, Serie Documentos: Madrid

DAVIS, A (1995): Magazine journalism today, Butterworth-Heinemann Ltd: Oxford

FABOAGA, C, SECANELLA, P.M (1987): Umbral de presencia de las mujeres en la prensa española. Serie estudios $\mathrm{n} \cong 1$. Alfonso Colomina: Madrid

FERNÁNDEZ SANZ, JJ (2000): ¡Qué informen ellos!, Huerga \& Fierro editores:

GOUGH-YATES, A (2003): Understanding Women's Magazines, Routledge: London

GALLEGO, J (1990): Mujeres de papel. De Hola a Vogue: La prensa femenina en la actualidad, Icaria: Barcelona.

HERMES J (1995): Reading Women's Magazines, Polity Press

JIMENEZ MORELL, I (1992): La prensa femenina en España (desde sus orígenes a 1868), La Torre: Madrid

PERINATS, A., MARRADES, M.J (1980): Mujer prensa y sociedad en España 1800-1934, C.I.S: Madrid

ROIG, M. (1989): La Mujer en la historia a través de la prensa. Ministerio de Asuntos Sociales. Instituto de la mujer: Madrid

SANCHEZ DÍAZ, A (2000): Prensa rosa, voto azul, Arakatzen S.L:

\section{Revistas}

CANTAZINO, B (2003): "La mujer en la prensa femenina del siglo XIX”, №2, Pamplona, Comunicación y sociedad

CONTROL (1989): "El medio revistas se debate entre la proliferación de títulos y la estacionalidad de la audiencia", №326, pp 39-72

ANUNCIOS (1987): Informe: Revistas femeninas, nํㅜ14, pp 17-29

ANUNCIOS (1989): "Ricas y famosas", no 386, pp 30-45

ANUNCIOS (1993): “G+J lanza una nueva Dunia”, № 589, pp 24-26

ANUNCIOS (1995): Especial revistas, no 648, pp 14-49

BLANCO, AA (1996): "Revistas. Remontando el vuelo", Ipmark, nº467, pp 44-66 
BLANCO, AA (1997): "Las ventas siguen cayendo", Ipmark, ํ483, pp 26-40

BLANCO, AA (1998): "Revistas. Nuevo retroceso", Ipmark, ํㅜ99, pp 38-55

BLANCO, AA (1999): "Revistas. Bajan las ventas, sube la publicidad", Ipmark, n517, pp $32-49$

BLANCO, AA (2001): "Todo sigue igual", Ipmark, n556, pp 74-90

DE HARO, F (1990): "Las revistas femeninas después del boom. El futuro se llama segmentación”, Ipmark, nำ359, pp 43-59

El Publicista (2003): "Revistas, todavía en negativo", no 91, pp 18-40

FERNANDEZ DEL VADO, S (1988): "Revistas femeninas. Un pastel de rica miel" Ipmark, n-317, pp 57-63

I PMARK (1992): “El 91 fue un mal año para las revistas femeninas”, no385, pp 21

IPMARK (1994): “La inversión en revistas femeninas descendió un 24\% en 1993”, nº426, pp18-19

IPMARK (2004): "Revistas 2004. Se rompe la tendencia negativa”, no 619, pp 35-60

MONTAÑES, F (2002): “Elena Sánchez Fabrés”, Ipmark, № 590, pp36-38

NOTICIAS DE LA COMUNICACION (1992): "Las revistas mensuales dirigidas a la mujer, optimistas ante la crisis", n-64, pp10-12

NOTICIAS DE LA COMUNICACION (1994): "Las revistas mensuales para la mujer resisten la crisis publicitaria y de difusión", nำ126, pp 4-14

NOTICIAS DE LA COMUNICACION (1996): "Las revistas también confían en la recuperación", nำ146, pp 20-34

NOTICIAS DE LA COMUNICACION (1997): "Las revistas recuperan la iniciativa para acabar con la crisis y aumentar ingresos", n-157, pp 30-130

NOTICIAS DE LA COMUNICACION (1998): "Las revistas se reaniman con la recuperación de la inversión publicitaria", №168, pp 44-162

NOTICIAS DE LA COMUNICACION (1999): "Las editoras de revistas aumentaron sus ingresos en 1997 un 17\%, que esperan superar en 1998", nำ179, pp 28-162

NOTICIAS DE LA COMUNICACION (2000): "Las editoras de revistas aumentaron sus ingresos un 8\% y redujeron sus beneficios en 1998", nำ190, pp 34-180

NOTICIAS DE LA COMUNICACION (2001): "Las editoras de revistas mantuvieron el aumento de sus ingresos y beneficios en 1999", ํㅡㄹㅣ, pp 48-186

NOTICIAS DE LA COMUNICACION (2002): “Las revistas viven la crisis con optimismo y confían en una pronta recuperación”, nำ212, pp 24- 171

NOTICIAS DE LA COMUNICACION (2003): "La crisis publicitaria y del mercado estanca la venta de las revistas y recorta sus resultados", n-223, pp 32-173

NOTICIAS DE LA COMUNICACION (2004): "Las revistas confían en la recuperación de la publicidad y de la audiencia para salir del estancamiento de sus ventas", no234, pp 44-189 
NOTICIAS DE LA COMUNICACION (2004): "El lanzamiento de 4 nuevos títulos convulsiona el mercado de revistas para la mujer", №240, pp 20-33

PRADO, JC (1994): "Revistas femeninas. Menos publicidad y más barata", Ipmark, n-429, pp 30-36

SANCHEZ, JJ (2003): "La publicidad y el enfoque de la imagen femenina", Comunicación y sociedad, Vol XVI, nำ2, diciembre, pp 67-92

(Recibido el 14-01-06, aceptado el 20-02-06) 